\title{
Preoperative evaluation of EDTA-dependent pseudothrombocytopenia before lumbar disc herniation surgery: A case report
}

\author{
Mustafa Sahin', Unsal Savci ${ }^{2}$, Havva Hande Keser Sahin ${ }^{3}$ \\ 'Department of Medical Biochemistry, Hitit University, Erol Olcok Education and Research Hospital, Corum, Turkey \\ ${ }^{2}$ Department of Medical Microbiology, Hitit University, Erol Olcok Education and Research Hospital, Corum, Turkey \\ ${ }^{3}$ Department of Pathology, Hitit University, Erol Olcok Education and Research Hospital, Corum, Turkey
}

\begin{abstract}
Ethylenediaminetetraacetic acid-dependent pseudothrombocytopenia (EDTA-PTCP) is an in vitro phenomenon characterized the clustering of platelets following the use of EDTA as an anticoagulant, leading to a decreased analyzer platelet count in a complete blood count (CBC). This report is a description of the case of a 47-year-old male patient admitted to a neurosurgery clinic with the complaints of back and leg pain. A neurological examination and lumbar magnetic resonance imaging revealing extruded disc herniations led to a decision to perform surgery. Thrombocytopenia was detected in the preoperative testing of the patient. The $C B C$ was reanalyzed using citrate. Peripheral blood smears of the patient collected using citrate and EDTA were compared. Thrombocytopenia was not detected in a CBC of the citrated sample and the peripheral smear did not reveal platelet clusters. Pseudothrombocytopenia was considered, as the anamnesis, physical examination findings, and coagulation tests of the patient were not consistent with thrombocytopenia. In conclusion, EDTA-PTCP was diagnosed during the preoperative evaluation of the patient.
\end{abstract}

Keywords: Citrate, EDTA-dependent pseudothrombocytopenia, peripheral blood smear

Ethoc) thylenediaminetetraacetic acid-dependent pseudothrombocytopenia (EDTA-PTCP) is an in vitro phenomenon defined as a false low platelet count measured by automated complete blood count $(\mathrm{CBC})$ analyzers as a result of platelet aggregation in the blood samples [1]. CBC analyzers may falsely evaluate large platelet clusters as a single, large platelet cluster or small lymphocytes [2]. EDTA is a well-known anticoagulant in use since the early 1950 s and has some advantages over other anticoagulants in practice [3]. The pathophysiology of EDTA-PTCP is not precisely known; however, it has been suggested that EDTA binds to calcium ions, interacts with the glycoprotein Ilb-Illa molecule on the platelet membrane, releases the glycoprotein Ilb epitope, and platelet aggregation occurs in patients with autoantibodies against the llb epitope
[4]. Although EDTA-PTCP is benign, it can lead to extra costs, patient anxiety, inappropriate diagnostic tests and transfusions, and even postponement of emergency treatments [2].

The aim of this study was to emphasize the importance of EDTA-PTCP in the evaluation of thrombocytopenia by presenting a case defined as EDTA-PTCP in the preoperative period.

\section{Case Report}

A 47-year-old male patient consulted the neurosurgery clinic with complaints of back and leg pain. On examination of the patient, a left femoral stretch test and left Lasègue test at $45^{\circ}$ was determined to be positive, and left ankle dorsiflexion was evaluated as $4 / 5$ muscle strength. Extruded disc herni-

Address for correspondence: Mustafa Sahin, MD. Department of Medical Biochemistry, Hitit University, Erol Olcok Education and Research Hospital, Corum, Turkey

Phone: +90 3642193000 E-mail: mustafaistanbulx@hotmail.com ORCID: 0000-0001-6073-563X

Submitted Date: February 09, 2018 Accepted Date: February 26, 2018 Available Online Date: June 01,2018

${ }^{\circ}$ Copyright 2018 by International Journal of Medical Biochemistry - Available online at www.internationalbiochemistry.com 


\begin{tabular}{|c|c|c|}
\hline Tests & $\begin{array}{l}\text { Patient } \\
\text { results }\end{array}$ & $\begin{array}{c}\text { Reference } \\
\text { interval }\end{array}$ \\
\hline International normalized ratio & 1.04 & $08-1.2$ \\
\hline Prothrombin time & 13.2 & $10.5-15 \mathrm{~s}$ \\
\hline $\begin{array}{l}\text { Activated partial } \\
\text { thromboplastin time }\end{array}$ & 26.9 & $21-38 s$ \\
\hline Fibrinogen & 228 & $150-400 \mathrm{mg} / \mathrm{dL}$ \\
\hline $\begin{array}{l}\text { Bleeding time } \\
\text { (manual practice) }\end{array}$ & 3.5 & $1-4 \min$ \\
\hline $\begin{array}{l}\text { Coagulation time } \\
\text { (manual practice) }\end{array}$ & 11 & 9-15 min \\
\hline
\end{tabular}

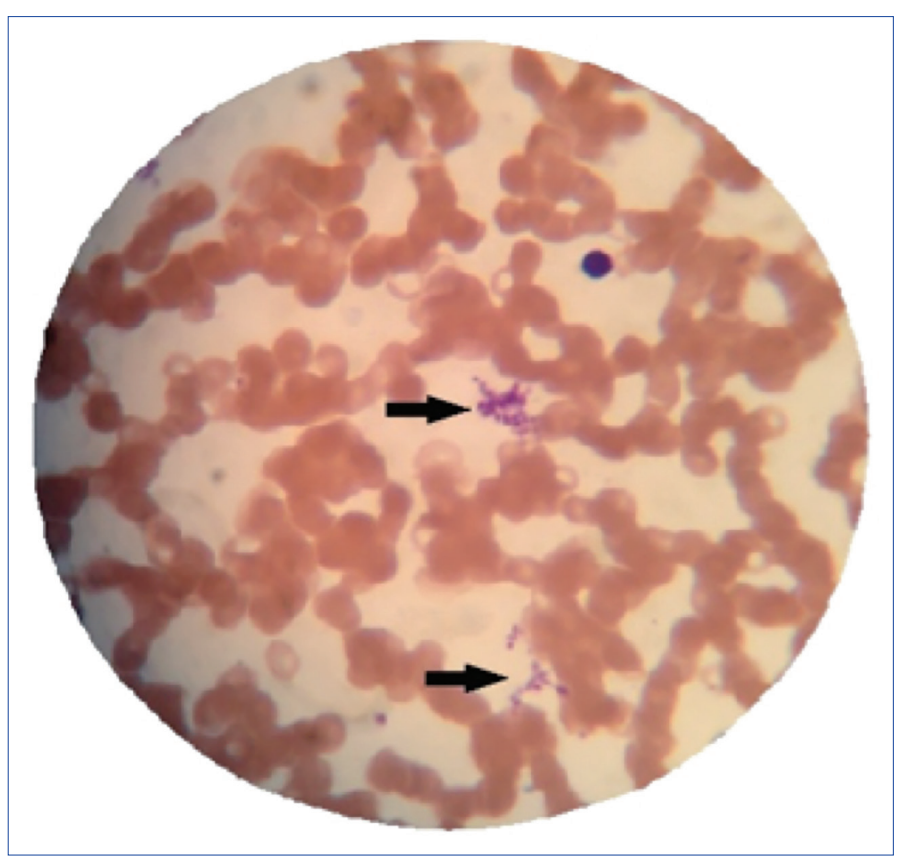

Figure 1. Platelet aggregation with ethylenediaminetetraacetic acid

ations were found at the L3-L4 and L4-L5 levels using magnetic resonance imaging. The patient was hospitalized ahead of a macroscopic discectomy operation on the herniated areas. The anesthesiologist requested preoperative laboratory tests. The platelet count was measured at $23 \times 103 / \mathrm{mm}^{3}$ and the sample was reanalyzed to confirm the result, which was evaluated as thrombocytopenia. Venous blood samples were collected using K3-EDTA tubes (Becton Dickinson and Co., Franklin Lakes, NJ, USA) and Vacuette sodium citrate tubes (Greiner Bio-One, Kremsmünster, Austria). Samples were measured in a Mindray BC6800 hematology analyzer (Mindray BioMedical Electronics Co. Ltd., Shenzen, China). A Sysmex CS2500 coagulation analyzer (Siemens Healthcare Diagnostics, Erlangen, Germany) was used for the coagulation tests. There were no physical examination findings of petechiae, purpura, or ecchymosis in the patient, and the coagulation test results were within the reference interval. The results are presented in Table 1.

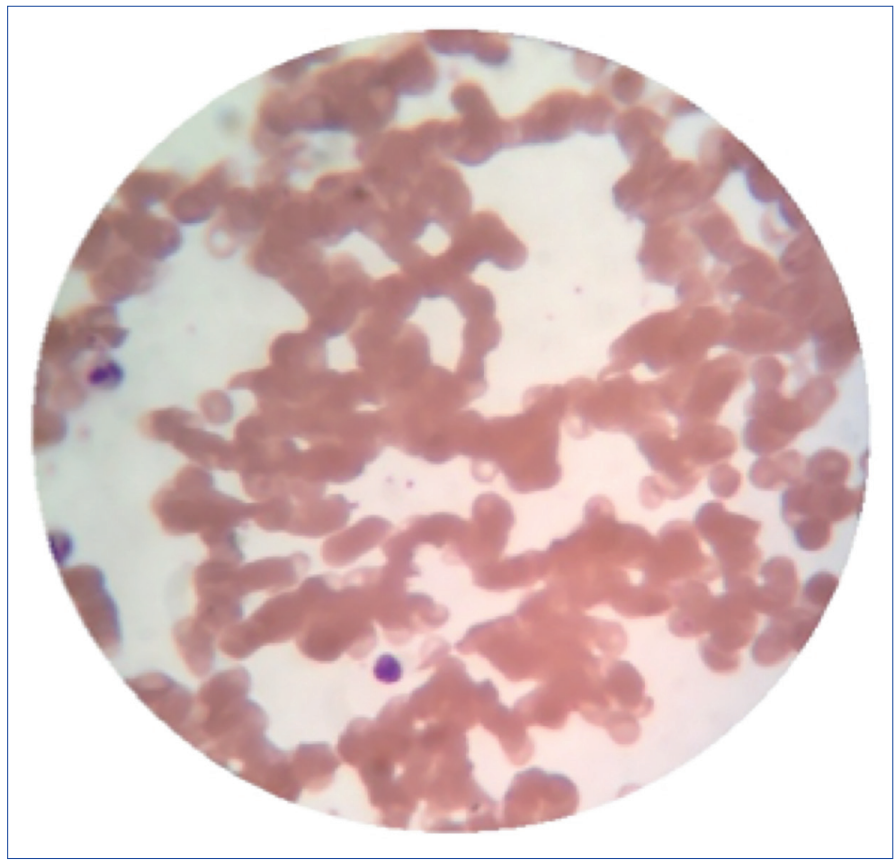

Figure 2. Homogeneous platelet distribution with citrate

EDTA-PTCP was considered in this case since the physical examination findings and coagulation tests were incompatible with the thrombocyte count. The patient's platelet count was repeated using a citrated tube, and the platelet count was $271 \times 103 / \mathrm{mm}^{3}$, which was within the normal reference interval. Peripheral blood smears collected using EDTA and citrate were examined and compared. Platelet clusters were not seen in the citrated blood sample, but were present in the EDTA-added blood sample (Fig. 1, 2). As a result of these laboratory tests, the patient was diagnosed with EDTA-PTCP. The results were evaluated by an anesthesiologist and the surgical operation was planned and performed without problem during the anesthesia process or the surgery. There was no postoperative bleeding and the patient was discharged from the hospital 2 days later.

\section{Discussion}

Although EDTA-PTCP is only seen in $0.1 \%$ of patients in locations providing routine health services, the incidence is $15 \%$ to $17 \%$ in centers investigating the etiology of thrombocytopenia [5]. EDTA-PTCP can be observed in healthy humans as well as in patients with various diseases. Pseudothrombocytopenia does not increase the risk of bleeding and platelet transfusion treatment is unnecessary. However, when the diagnosis of EDTA-PTCP is missed, it may cause unnecessary treatment interventions, such as a transfusion, or even a splenectomy [4]. In this case, pseudothrombocytopenia was not missed because the absence of physical examination findings of ecchymosis or purpura in a patient with a low platelet count was noted preoperatively, and EDTA-PTCP was diagnosed upon reassessment. EDTA-dependent pseudothrombocytopenia is the most common, but PTCP dependent on the anticoagulants citrate, heparin, and sodium fluoride has also been described 
[6]. Many brands and models of automated hematology analyzers are used to perform a CBC in health institutions around the world. Currently, there is no hematology analyzer that can directly alert the user about EDTA-PTCP, but some analyzers can present information such as "platelet aggregation,"“"platelet clusters," or "platelet clumps." Each brand of analyzer uses different terminology. Cases of platelet aggregation warnings or patient samples with thrombocytopenia should be considered for EDTA-PTCP, and laboratory staff should evaluate these warnings for further diagnostic tests. Hematology laboratories can be important in the identification of patients with pseudothrombocytopenia and assist the physician. Various methods are used to distinguish between pseudothrombocytopenia and real thrombocytopenia. Microscopic observation of platelet clusters in a peripheral blood smear is accepted as the gold standard for the detection of EDTA-PTCP. Other methods include the use of other anticoagulants, such as sodium citrate, oxalate, and heparin in place of EDTA; the analysis of EDTA blood at $37^{\circ} \mathrm{C}$; and the addition of kanamycin to blood samples $[7,8]$. When EDTAPTCP is suspected, the easiest method is to study citrated blood samples in $C B C$ analyzers to find the true platelet count [8]. The platelet count of a citrated sample will be higher than the platelet count of an EDTA sample in these cases. If this cannot be realized, it could lead to some serious consequences, such as misdiagnosis, unnecessary laboratory tests or treatment, and postponement of emergency surgery.

As a result, physicians should contact the laboratory in the case of thrombocytopenia results that are incompatible with physical examination findings and coagulation tests. Laboratory staff should also be educated and careful about EDTA-PTCP and form an algorithm for thrombocytopenic and warnings of platelet aggregation in samples. This may include reanalyzing the suspected sample and using other anticoagulants, such as citrate, to examine a peripheral blood smear. We believe that these precautions can reduce misdiagnosis by discriminating between pseudothrombocytopenia and real thrombocytopenia, and prevent unnecessary laboratory testing and medical interventions.

The patient in this case provided written, informed consent.
Funding Sources: None.

Conflict of interest: None declared.

Peer-review: Externally peer-reviewed.

Authorship contributions: Concept - M.S., U.S., H.H.K.S.; Design - M.S., U.S.; Supervision - M.S., U.S.; Fundings - H.H.K.S., M.S.; Materials - M.S., U.S.; Data collection \&/or processing - M.S., H.H.K.S.; Analysis and/or interpretation - U.S., H.H.K.S., M.S.; Literature search - M.S., U.S., H.H.K.S.; Writing - M.S., U.S., H.H.K.S.; Critical review - M.S., U.S., H.H.K.S.

\section{References}

1. Kamath V, Sarda P, Chacko MP, Sitaram U. Pseudothrombocytopenia observed with ethylene diamine tetra acetate and citrate anticoagulants, resolved using $37^{\circ} \mathrm{C}$ incubation and Kanamycin. Indian J Pathol Microbiol 2013;56:306-8. [CrossRef]

2. Nagler M, Keller P, Siegrist D, Alberio L. A case of EDTA-dependent pseudothrombocytopenia: simple recognition of an underdiagnosed and misleading phenomenon. BMC Clin Pathol 2014;14:19. [CrossRef]

3. Hadley GG, Larson NL. Use of sequestrene as an anticoagulant. Am J Clin Pathol 1953;23:613-8. [CrossRef]

4. Keti DB, Muhtaroğlu S, Kalay N. Antikoagülanların tam kan sayımına etkisi:EDTA'ya bağlı psödotrombositopeni. Türkiye Klinikleri Biyokimya Dergisi. 2015;13:79-82.

5. Canpolat G, Koçak-Tufan Z, Bulut C, Alioğlu B, Kınıklı S, Demiröz AP. EDTA'ya Bağlı Psödotrombositopeni Sonucu Gereksiz Transfüzyon Yapılan Bir Kırım-Kongo Kanamalı Ateşi Olgusu. Klimik Journal/Klimik Dergisi 2011;24.

6. Kovacs F, Varga M, Pataki Z, Rigo E. Pseudothrombocytopenia with multiple anticoagulant sample collection tubes. Interventional Medicine \& Applied Science, 2016;8:181-3. [CrossRef]

7. Bizzaro N. EDTA-dependent pseudothrombocytopenia: a clinical and epidemiological study of 112 cases, with 10-year follow-up. Am J Hematol 1995;50:103-9. [CrossRef]

8. Ozcelik F, Arslan E, Serdar MA, Yiginer O, Oztosun M, Kayadibi $H$, et al. A useful method for the detection of ethylenediaminetetraacetic acid- and cold agglutinin-dependent pseudothrombocytopenia. Am J Med Sci 2012;344:357-62. [CrossRef] 